\title{
Disparities in Knowledge Employees' Actual, Contractual, and Desired Working Schedules
}

\author{
Raul Ruubel, ${ }^{1}$ Tallinn University of Technology, Estonia \\ Aaro Hazak, Tallinn University of Technology, Estonia
}

\begin{abstract}
Our study on a sample of Estonian creative knowledge employees indicates considerable disparities between their actual, contractually agreed, and desired amounts of working time. Nearly two thirds of the employees studied exhibited a mismatch between their desired and contractual working schedules, reflecting the constraints that employment contracts set on preferred working time. Our study results reveal that even if the employees had access to flexible working time options, a majority of them still followed roughly the standard nine-to-five working schedule even though their desired timing of work may have been different. This may be driven by various social norms and family commitments that warrant further study. The actual duration of the working day is longer than contractually agreed for 90 percent of the employees studied, which may pose health risks to employees. Our ordinary least squares (OLS) regression estimates show that the more educated the employee is, the less overtime work they did, while the higher their salary level, the more hours of overtime the employee did. The OLS regression estimates for the time difference between the actual start and the contractual start of the working day show that women tended to start their working day later and men earlier than officially required. Interestingly, the larger the family the employee had, the more the actual start time of work shifted to being earlier than contractually required. The older the employee, the later the start of their working day was from the official schedule. Our study highlights potentially large inefficiencies in industrial relations and in the use of the potential of employees in creative knowledge work that may have considerable adverse effects on the financial results of companies and on socio-economic development in general.
\end{abstract}

Keywords: Working Schedules, Preferences, Mismatch, R\&D Jobs, Estonia

\section{Introduction}

$\mathrm{D}$ ifferences between actual and desired working schedules may indicate inefficiencies in the labour market, as unfavourable working arrangements may constrain employment and result in wages being suboptimal, both of which have adverse effects on the financial performance and competitive advantages of companies. Moreover, the intellectual capacity of knowledge employees may be used less effectively if there is a mismatch between actual and desired working time as the employees might not be able to contribute as much as they potentially could. However, the costs for the employer may remain the same or may even be higher than they would if the employees were allowed to choose their working schedules freely.

Actual working schedules differing from contractual ones may put the health of knowledge employees at risk if they have to work considerably more than contractually agreed or than is stipulated in statutory employment regulations, or it may result in legal risks if the actual working schedules remain different from the officially agreed ones. It is therefore important to understand how significant the differences between actual, contractually agreed, and desired working hours are, and the types of employee most likely to feel these disparities. This would be useful for rethinking the contractual terms of employment so that employees could work at the times they preferred, from which their employers may gain in their financial and operational results. Moreover, knowing the differences between the actual and desired working schedules may help in the design of further studies on the economic and financial efficiency of working arrangements and could initiate a public discussion about the underlying social norms and other institutional issues that should perhaps be reconsidered, such as attitudes and regulations surrounding the timing, place, and broader organisation of work.

\footnotetext{
${ }^{1}$ Corresponding Author: Raul Ruubel, Akadeemia tee 3, Department of Economics and Finance, Tallinn University of Technology, Tallinn, 12611, Estonia. email: raul.ruubel@ttu.ee
}

Knowledge Management: An International Journal

Volume 18, Issue 1-2, 2018, http://organization-studies.com

(C) Common Ground Research Networks, Raul Ruubel, Aaro Hazak,

Some Rights Reserved, (CC BY-NC-ND 4.0). Permissions: support@cgnetworks.org

ISSN: 2327-7998 (Print) 2327-9249 (Online)

http://doi.org/10.18848/2327-7998/CGP/v18i01/17-30 (Article) 
Our study of Estonian employees working in creative research and development (R\&D) aims to shed light on the drivers of their actual, contractual, and desired working hours, and the extent of disparities between those sets of hours. Creative knowledge work is a specific area of activity where rigid working schedules may be much less necessary than in some other jobs. Although there has been a clear change in the nature of work away from manual and routine work and towards more creative and intellectual work in increasingly knowledge-based advanced economies, changes to work arrangements may not have kept pace with the intensification of knowledge. This makes the study of the discrepancies between the actual, desired, and contractually agreed organisation of work in knowledge jobs a particularly interesting and relevant topic. Moreover, knowledge-intensive work and innovation is critical for economic development and the efficiency of it may be crucial for companies to achieve competitive advantages and improve their financial results in a globally competitive market.

For a theoretical framework, Tan (2018) argues that more freedom at work leads to better work results from knowledge employees given that the more flexible the working arrangements are and the less control there is over the employee, the larger the informational asymmetry is between the employer and the knowledge employee about the innovative work. The theoretical argumentation by Tan (2018) suggests that the informational asymmetry is in the interest of the employer because it means the outcomes of the innovative work have to be shared more fairly between the employer and the employee, and so flexible work arrangements have an important role in encouraging the employee to innovate.

This pilot study is based on a relatively small sample of employees from a specific industry and a specific country, and so the results cannot be broadly generalised. However, this exploratory empirical study is needed to understand better whether the disparities in the actual, contractual, and desired working schedules of knowledge employees are significant, and which of these discrepancies would warrant further study.

\section{Literature}

Numerous studies have shown that employees are not usually able to choose their desired working hours, and quite a substantial number of employees have a mismatch between their preferences and their actual working time. This contradicts the neoclassical theory of labour supply, which assumes that employees are free to choose their working hours. Böheim and Taylor (2004) find, for instance, that some 40 percent of full-time British employees would prefer to work fewer hours than they actually do. Barnay (2016) concludes that 29 percent of European employees would like to work less than they do, which is a significant proportion given that several studies (e.g. Bell, Otterbach, and Sousa-Poza 2012; Moen et al. 2011; Hazak et al. forthcoming) have found that unwanted long hours are likely to have an adverse impact on perceived health and wellbeing, because of increased emotional stress, tiredness, and sleepiness, and that they lead to lower levels of job satisfaction (e.g. Green and Tsitsianis 2005; Hazak et al. 2016). Studying a much broader set of work arrangements than the time aspects in the European working conditions survey, Barnay (2016) further stresses that having appropriate working conditions plays a protective role for the physical and emotional health of the employee, while working more than desired has a harmful impact on health; he concludes that existing studies already encourage employers to consider the preferences of employees more when setting working hours.

Van Wanrooy (2013) finds that Australian employees tend to prefer a standard forty-hour working week, but over the past few decades the hours of full-time Australian employees have been increasing steadily. Her findings suggest that on average men prefer to work around forty hours a week and women twenty-eight to thirty, and that various demographic and work factors such as age, the current actual number of hours worked, and the share of paid work in the household contribute further to the mismatch with desired working hours. Kossek, Barber, and Winters (1999) study the use of flexible working schedules and find that women and younger 
employees are more likely to take advantage of them. Similarly, Sharpe, Hermsen, and Billings (2002) find younger employees, those who are more educated, and those with young children to be more likely to use flexible schedules, while Virkebau and Hazak (2017) find the impact to be the opposite for employees with children in the family below school-age, where the daily routine of family life may create a demand for fixed schedules whatever the creative needs of the work. Hazak, Ruubel, and Virkebau (forthcoming) find in a study using data from the same survey of Estonian R\&D employees that only one quarter of employees favoured a standard five-day working week, while more than half would prefer a working week concentrated in three or four days, with the differences in preferences explained by gender, education, health, sleeping hours, whether the employee is of morning type or evening type as their inherent circadian rhythms leave them more alert in the morning or in the evening, and the desired share of time spent on creative work.

Bryan (2007) uses matched employer-employee data and finds that weekly working hours in the United Kingdom depend mainly on the employer and that switching employer to gain more suitable working hours appears to be a common tactic for employees. He also finds some support for the use of within-firm flexibility, or job-switching within a firm. The results of Bryan (2007) indicate that both skills and family characteristics have a strong impact on working hours. Sousa-Poza and Henneberger (2000) find that men tend to prefer longer working hours than women do, while older men want fewer working hours than younger men do. In addition, women with higher levels of education and employees with better job security and higher incomes tend to prefer to work less than they actually do. Another perspective on the discrepancies between actual hours working and desired hours is given by Väisänen and Nätti (2002), who observe a mismatch between actual and preferred household working time in the European Union countries and Norway, where dual-earner households were on average overworked rather than underworked and were willing to reduce their working time by an average of twelve hours a week. They find that preferences for working hours can be explained by caring responsibilities, education, and the regulatory context in each country.

Van Echtelt et al. (2006) focus on the gap between actual and preferred working hours in Dutch companies, finding limited support for the hypothesis that over-employment is caused by restrictions imposed by the employer, while demonstrating that more flexibility in the labour market and a broader set of institutional factors, combined with job design and organisational incentives, can impact the way individuals make their decisions about working time. They suggest that greater job autonomy makes it more likely that working time decisions will be based on the need to complete specific tasks or projects, with the employee consequently working more hours than they would prefer to.

Van Emmerik and Sanders (2005) find that a mismatch in working hours is associated with affective job commitment, where the impacts are different for those who prefer to work less and those who prefer to work more. Employees who favour working fewer hours showed less affective commitment, while employees who work more hours than they would prefer to appeared to become more committed. While the reasons for that finding warrant further study, the finding itself provides an additional insight into the complex linkages between individual preferences for working hours and the attitude toward work. Otterbach (2010) finds support for the mismatch in working hours in his study of twenty-one countries, showing that more than a third of the employees studied faced working time constraints, and that these constraints have increased over recent decades. He finds that the differences between countries are interrelated with key macroeconomic variables such as the unemployment rate, GDP per capita, average weekly hours of work, and income inequality, showing that in countries with high unemployment rates, relatively more employees prefer to have additional working hours and earnings, while in only a few wealthy countries are there large shares of employees who would like to work longer and earn more. The results of Otterbach (2010) further suggest that the desire to work more or fewer hours is strongly related to income considerations and the expected employment situation. 
Knowledge work in the area of research and development (R\&D), on which our study is focused, is a specific case given that high knowledge intensity in a business may be accompanied by increased credit constraints and difficulties in getting financing because of the high risks involved and the poor ability of the companies to provide collateral for the financing that is needed for R\&D investment (Männasoo and Meriküll 2014). Difficulties in getting external financing may lead to low leverage and constraints on investment, and the reduced intensity of investment may in turn have adverse consequences for how productively the intellectual capital and labour can be utilised and for the overall financial performance of the company (see Kotšina and Hazak 2012; Hazak 2008; Männasoo, Maripuu, and Hazak 2018; Avarmaa, Hazak, and Männasoo 2014; among others). In parallel to these features, knowledge work is heavily reliant on the ability of the employee to produce creative outcomes. Creative knowledge jobs may therefore require employers to pay extra attention to providing favourable work arrangements for their employees as the entire business and its financial performance are heavily reliant on how efficiently the intellectual capital of the employees is used (see Coenen and Wok 2014; Kelliher and Anderson 2008; Nätti et al. 2012).

While several studies have focused on the mismatch between actual and desired hours, to the best of our knowledge, no studies have focused on the difference between actual and contractual working hours, which is addressed in this study. We put more focus on the mismatch between the actual and desired start and end times of the working day than previous studies on the mismatch in working hours have.

\section{Data and Methodology}

This study draws on our original repeated survey among creative R\&D employees in Estonia, conducted in two waves in 2015 and 2016. Out of all those reported as R\&D employees in Estonia in the Statistics Estonia dataset, our focus is on the category of "researchers" so we can capture knowledge employees whose work is creative in nature. From 2010 to 2014, the number of full-time-equivalent creative R\&D employees classed as "researchers" in Estonia ranged between 4,100 and 4,600 according to the Statistics Estonia data. In compiling our study sample, we have disregarded those creative $R \& D$ employees who were working in higher education and healthcare because their working arrangements with fixed times for lectures and medical procedures may be substantially different from those in other creative R\&D jobs. Furthermore, employees working at microenterprises and research institutes with fewer than fifteen creative $R \& D$ employees were also excluded. As a result of these exclusions, the population of knowledge employees of interest for our study totalled approximately 1,000, and our final survey sample of 153 employees represents about 15 percent of that population, which is a normal sample size for a voluntary full population survey. The sample can be smaller for some of the analysis presented in this article however, depending on the number of employees who provided answers to the specific questions addressed in this study, such as the contractual, desired, and actual start and end times of their working days and the duration of their actual working day.

There may be some selection bias in the decision by a respondent to complete the survey or not to complete it, and further selection biases may arise since employees could participate in the survey only if their employer agreed to take part in the project. We address these selection issues by weighting the sample to align it with the characteristics of the target population for the respondent's gender and the employer's sector of business. As the Statistics Estonia dataset shows the distribution of the employers by their area of business and the gender split of the employees in the total population of interest of around 1,000 employees, we have assigned a weight to each observation in our final sample to reflect the gender and the area of business of the observation. As a consequence the distribution of the areas of business of the employers and the gender distribution of employees in the weighted sample matches the population of interest. Another measure we use to address the employer-driven selection issues is clustering of standard errors by employers in the regression models. 
We use the following dependent variables in the two regression models presented in this article: (1) the difference between the contractual and actual duration of a working day (duration_dif), and (2) the difference between the contractual and actual start times of the working day (start_dif). The subsamples for the analysis of the differences between the actual, contractual, and desired end times of the working day, and the desired and actual and desired and contractual start times of the working day were too small for meaningful regression analysis to be conducted, but we present some findings based on descriptive statistical analysis in the Results and Discussion section for those.

Independent variables were selected in view of the earlier literature. Age, gender, number of family members, and years of education are important socio-demographic characteristics, and the health factor reflects the general health of the employee (see Table 1 for details of the composition of the health factor). The score of the Reduced Morningness-Eveningness Questionnaire by Adan and Almirall (1991), which has been extensively used in medical research into sleep, shows the morningness-eveningness preference of the employee, and the average daily hours of sleep is another independent variable. The desired creative intensity of work, which is the share of their total working time that the employee wants to spend on creative work, and the salary level reflect aspects specific to the job.

The explanatory variables have been outlined in Table 1 with descriptive statistics of all the 153 employees studied; the ninety employees for whom the difference between the contractual and actual durations of the working day (duration_dif) was available, meaning those who have contractually agreed working hours; and the sixty-five employees for whom the difference between the contractual and actual start times of the working day (start_dif) could be studied, which is those who have contractually agreed working hours and a regular actual starting time for daily work. We note the limitations of the study that arise from the relatively small sample size.

To identify simultaneously the significance and magnitude of the explanatory variables of interest and the other control variables for the extent of the difference between the contractual and actual durations of the working day (duration_dif) and the difference between the contractual and actual start times of the working day (start_dif), we use an ordinary least squares (OLS) regression for the two dependent variables duration_dif and start_dif for the econometric analysis. For the other aspects of the disparities between the actual, contractual, and desired working schedules, descriptive statistical analysis has been used given the small subsample sizes. 
Table 1: Explanatory Variables and Description of the Subjects

(Mean and Standard Deviation Shown for Continuous and Ordered Variables;

Percentage of Respondents Shown for Binary and Categorical Variables)

\begin{tabular}{|c|c|c|c|c|}
\hline Variable & Description & $\begin{array}{r}\text { All } \\
\text { Mean/\% } \\
\text { (Std. } \\
\text { Dev.) }\end{array}$ & $\begin{array}{r}\text { duration_dif } \\
\text { Mean } / \% \\
\text { (Std. Dev.) }\end{array}$ & $\begin{array}{r}\text { start_dif } \\
\text { Mean } / \% \\
\text { (Std. } \\
\text { Dev.) }\end{array}$ \\
\hline & $\mathrm{N}$ & 153 & 90 & 65 \\
\hline age & Age in years & $\begin{array}{r}38.76 \\
(11.51)\end{array}$ & $\begin{array}{r}38.46 \\
(10.96)\end{array}$ & $\begin{array}{r}38.09 \\
(10.87)\end{array}$ \\
\hline gender & $\begin{array}{l}\text { Male }(=1) \text { vs. female }(=0) \text {; the figures in the } \\
\text { cells to the left show the percentage of males }\end{array}$ & $56.9 \%$ & $52.2 \%$ & $38.1 \%$ \\
\hline family & $\begin{array}{l}\text { Employee reported number of people living } \\
\text { together with the employee }\end{array}$ & $\begin{array}{r}1.66 \\
(1.46)\end{array}$ & $\begin{array}{r}1.76 \\
(1.42)\end{array}$ & $\begin{array}{r}1.85 \\
(1.55)\end{array}$ \\
\hline $\begin{array}{l}\text { education } \\
\text { (years) }\end{array}$ & $\begin{array}{l}\text { Years of education starting from primary } \\
\text { education }\end{array}$ & $\begin{array}{l}16.58 \\
(2.66)\end{array}$ & $\begin{array}{l}16.18 \\
(2.37)\end{array}$ & $\begin{array}{l}15.74 \\
(2.35)\end{array}$ \\
\hline fhealth & General health condition factor with overall & 0.00 & -0.01 & -0.01 \\
\hline (factor) & $\begin{array}{l}\text { Kaiser-Meyer-Olkin measure of sampling } \\
\text { adequacy of the factor } 0.6 \text {; comprising (1) "Do } \\
\text { you have high blood pressure or have you ever } \\
\text { used medicine for high blood pressure?" (yes=1); } \\
\text { (2) "Do you suffer or have you suffered from } \\
\text { diseases that significantly affect your mental } \\
\text { fatigue?" (5-level Likert type scale, "Never"=1, } \\
\text { "Often"=5); (3) "Does any disease or injury } \\
\text { interrupt you while doing your daily work?" (5- } \\
\text { level Likert type scale, "No obstacles"=1, "Not } \\
\text { able to work"=5); (4) "How many working days } \\
\text { have you been absent from work due to disease } \\
\text { or medical examination in the past } 12 \\
\text { months?"(5-level scale, "None" = 1, "100-365 } \\
\text { days" = 5); (5) Body-Mass Index (continuous) }\end{array}$ & $(0.81)$ & $(0.82)$ & $(0.76)$ \\
\hline meq & $\begin{array}{l}\text { rMEQ score, } 1 \ldots 25 \text { scale ranging from } \\
\text { "Definitely an evening type" to "Definitely a } \\
\text { morning type" }\end{array}$ & $\begin{array}{r}14.73 \\
(3.53)\end{array}$ & $\begin{array}{r}14.64 \\
(3.39)\end{array}$ & $\begin{array}{r}15.02 \\
(3.35)\end{array}$ \\
\hline \multirow[t]{6}{*}{ sleephours } & $\begin{array}{l}\text { Employee reported average sleeping hours per } \\
\text { day on the scale: }\end{array}$ & & & \\
\hline & "Less than 6 hours" (base) & $7 \%$ & $4 \%$ & $5 \%$ \\
\hline & “6-7 hours” (= 2) & $50 \%$ & $54 \%$ & $55 \%$ \\
\hline & “7-8 hours" (= 3$)$ & $38 \%$ & $37 \%$ & $34 \%$ \\
\hline & "8-9 hours" $(=4)$ & $6 \%$ & $4 \%$ & $6 \%$ \\
\hline & "more than 9 hours" $(=5)$ & $0 \%$ & $0 \%$ & $0 \%$ \\
\hline creatime & $\begin{array}{l}\text { Employee desired share of creative work in total } \\
\text { working time of the employee (\%) }\end{array}$ & $\begin{array}{r}52.71 \\
(21.43)\end{array}$ & $\begin{array}{r}49.22 \\
(21.15)\end{array}$ & $\begin{array}{r}46.69 \\
(20.90)\end{array}$ \\
\hline \multirow[t]{6}{*}{ salary } & $\begin{array}{l}\text { Employee reported monthly gross salary on the } \\
\text { scale: }\end{array}$ & & & \\
\hline & "Below 1000 euros" (=1, base) & $7 \%$ & $4 \%$ & $3 \%$ \\
\hline & "1000 - 2000 euros" $(=2)$ & $58 \%$ & $54 \%$ & $52 \%$ \\
\hline & "2000 - 3000 euros" $(=3)$ & $23 \%$ & $37 \%$ & $32 \%$ \\
\hline & “3000 - 5000 euros" $(=4)$ & $11 \%$ & $4 \%$ & $11 \%$ \\
\hline & "above 5000 euros" (=5) & $1 \%$ & $0 \%$ & $2 \%$ \\
\hline
\end{tabular}

Source: Authors 2018 


\section{Results and Discussion}

First, we present the distributional patterns of the actual, contractually agreed and desired start and end times of working days in the histograms in Figure 1. The rightmost panels on the desired start and end time of the working day reflect only those participants in the survey who would like to have a fixed start and end time for their working day and does not include the 57 percent of sample members who prefer to have irregular working hours. The left and middle panels of Figure 1 on the actual and contractual start and end times of the working day, however, include those employees who prefer flexible schedules. When interpreting the rightmost histograms it should therefore be noted that those who expressed a desired start or end time for their working day and whose preferences are depicted on the figure are a specific type of employee separate from those who would like to start or end their work at different times on different days and whose preferences are not reflected in the figure.
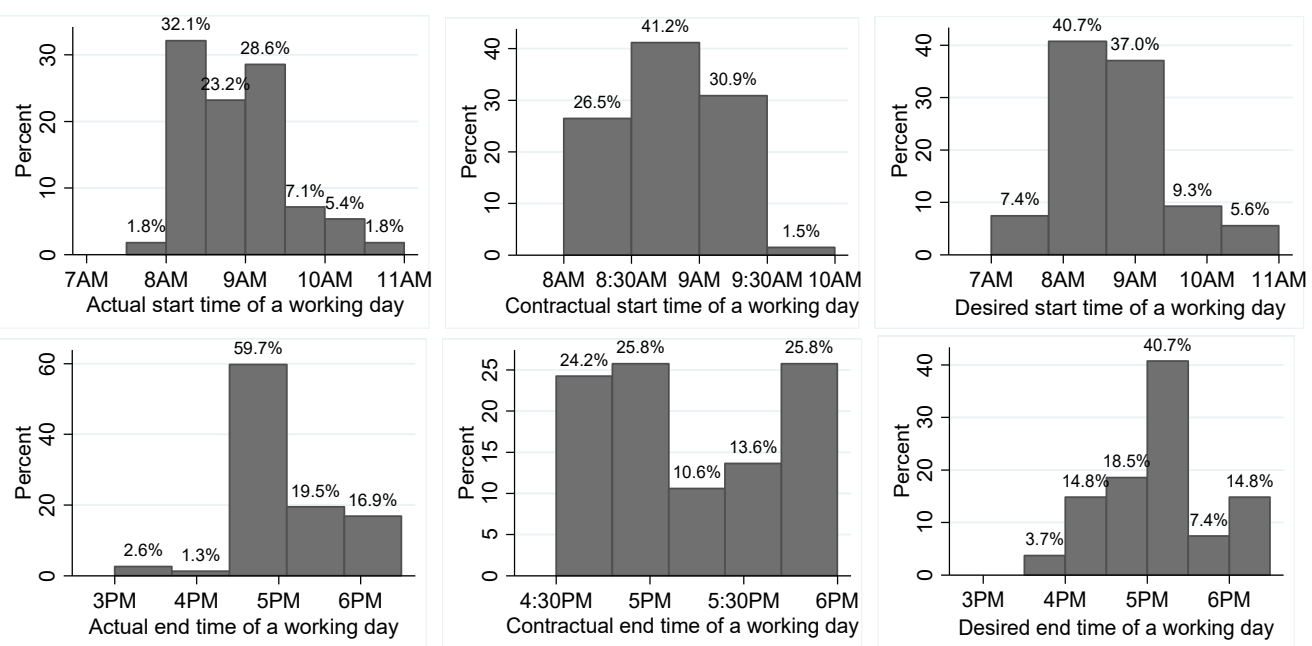

Figure 1: Distribution of Actual, Contractual and Desired Start, and End Times of the Working Day Source: Authors 2018

It appears that in our subsample, the contractual start and end times of the working day are overall in line with the traditional standard hours, while the actual and desired start and end times have a broader variance. Overall, a majority of creative R\&D employees in our subsample end their working day near the traditional time of 5 p.m., whereas the contractual end time of the working day is more evenly distributed between 4:30 p.m. and 6 p.m. As 70 percent of the employees in our subsample finish their working day at the contractually agreed time, and the mismatch is not significant for those who experience one, the mismatch between the contractual and actual end times of the working day does not in general appear to be an issue of major concern for our quite small study sample. However, studies on a larger sample would be needed to provide further evidence for this. Disparities between the contractual and actual start times of the working day seem to be more evident, as 40 percent the respondents exhibit a deviation between the actual start time and the contractually agreed one and, as illustrated in Figure 1, many of these deviations are large. The results of the regression analysis presented below seek to explain what type of employee experiences these disparities and to what extent.

The differences between the desired and actual start times of the working day in our subsample show that 19 percent of the employees who would like to have a fixed start for a working day would prefer to start earlier than they actually do, while 39 percent of the respondents would prefer to start their working day later than they do. For the end time of the 
working day, 35 percent of those who would like to have a fixed end time for the working day would want to end earlier than they actually do and 13 percent later, indicating that for some of the employees the working day they desire may be shorter than their actual working day, which is line with previous literature (e.g. Böheim and Taylor 2004; Barnay 2016). The large and heterogeneous mismatch between the desired and actual start and end times of the working day is therefore an issue that warrants further study on larger samples from different industries and countries using sophisticated econometric analysis.

Interesting results appear when the start and end times of the working day are studied for those employees who have the option of flexitime. A majority of the knowledge employees in our sample who can choose a flexible working schedule still follow schedules that are quite similar to the standard nine-to-five routine, although the timing they desire for their work may be different. Among the employees who have the option of flexitime, 57 percent start their working day between 8 a.m. and 9 a.m., and 41 percent finish their working day between 4:30 p.m. and 5:30 p.m. Moreover, 38 percent of the employees with flexitime start between 8 a.m. and 9 a.m. and end between 4:30 p.m. and 5:30 p.m. Various social norms and family commitments may explain this behaviour, but it warrants further study. Past research (e.g. Sharpe, Hermsen, and Billings 2002; Van Echtelt et al. 2006) suggests the reasons may lie in the fixed daily routines of children, spouses or other family members, social norms for what are normal working hours, and conventional fixed daily mealtimes, sleep times and other routines. Though these possible reasons remain purely hypothetical in this article, the study of them remains an interesting and promising avenue for future research.

Among the employees in our subsample, 93 percent had a mismatch between the actual and contractual durations of their working day, indicating that contractual working schedules do not reflect the reality, whether the difference is due to the employee or the employer. Moreover, for 90 percent of the employees studied, the actual working day lasted longer than the contractual day, which may pose health risks to knowledge employees and lead to them having a lower level of job satisfaction (e.g. Bell, Otterbach and Sousa-Poza 2012; Moen et al. 2011; Green and Tsitsianis 2005). The regression analysis presented below aims to identify what type of employee experiences the mismatch between the actual and contractually agreed durations of the working day and to what extent.

Analysis of the disparities between the desired and contractually agreed start and end times of the working day shows almost two thirds of the employees in our subsample experienced a mismatch. This reflects how the contractual arrangement of working hours may constrain the use of desired work schedules not only for those who would like to have flexible schedules but also for those who prefer to have a fixed component in their working day schedule as well. This potentially serious inefficiency in contractual working arrangements in creative knowledge work warrants further study on larger samples.

Next, we will move to the regression models to investigate what type of employee exhibits some of the more serious mismatches in working hours discussed above. Table 2 outlines the OLS estimates of the difference between the actual and contractual durations of the working day (Models 1 and 2), and the difference between the contractual and actual start times of the working day (Models 3 and 4). The difference between the specifications of Models 1 and 2 and 3 and 4 lies in whether average sleeping hours are included among the explanatory variables or not, given that there may be a potential reverse causality if employees who work more extended hours have fewer sleeping hours. However, both specifications of both of the models have similar results. The R-squared ranging between 0.2 and 0.4 in these models suggests the working hours mismatch is driven not only by the variables incorporated in the model but also by various other individual and possibly behavioural factors and employer related factors that could derive from organisation culture and the work environment. 
Table 2: OLS Estimates of duration dif and start dif

\begin{tabular}{|c|c|c|c|c|}
\hline Explanatory Variable & $\begin{array}{l}\text { Model 1 } \\
\text { duration_dif }\end{array}$ & $\begin{array}{l}\text { Model } 2 \\
\text { duration_dif }\end{array}$ & $\begin{array}{l}\text { Model } 3 \\
\text { start_dif }\end{array}$ & $\begin{array}{l}\text { Model } 4 \\
\text { start_dif }\end{array}$ \\
\hline creatime & $\begin{array}{l}0.005 \\
(0.00)\end{array}$ & $\begin{array}{l}0.003 \\
(0.00)\end{array}$ & $\begin{array}{l}0.000 \\
(0.00)\end{array}$ & $\begin{array}{l}0.000 \\
(0.00)\end{array}$ \\
\hline age & $\begin{array}{l}-0.004 \\
(0.01)\end{array}$ & $\begin{array}{l}-0.004 \\
(0.01)\end{array}$ & $\begin{array}{l}-0.014^{* * *} \\
(0.00)\end{array}$ & $\begin{array}{l}-0.014 * * * \\
(0.00)\end{array}$ \\
\hline gender $($ Male $=1)$ & $\begin{array}{l}0.153 \\
(0.17)\end{array}$ & $\begin{array}{l}0.258 \\
(0.18)\end{array}$ & $\begin{array}{l}0.406^{* * *} \\
(0.12)\end{array}$ & $\begin{array}{l}0.413 * * \\
(0.12)\end{array}$ \\
\hline family & $\begin{array}{l}0.025 \\
(0.10)\end{array}$ & $\begin{array}{l}0.034 \\
(0.10)\end{array}$ & $\begin{array}{l}0.082 * \\
(0.04)\end{array}$ & $\begin{array}{l}0.083^{*} \\
(0.04)\end{array}$ \\
\hline educationy & $\begin{array}{l}0.072 * \\
(0.04)\end{array}$ & $\begin{array}{l}0.087^{*} \\
(0.04)\end{array}$ & $\begin{array}{l}0.012 \\
(0.02)\end{array}$ & $\begin{array}{l}0.015 \\
(0.02)\end{array}$ \\
\hline fhealth (factor) & $\begin{array}{l}0.060 \\
(0.10)\end{array}$ & $\begin{array}{l}0.088 \\
(0.08)\end{array}$ & $\begin{array}{l}-0.055 \\
(0.09)\end{array}$ & $\begin{array}{l}-0.042 \\
(0.09)\end{array}$ \\
\hline meq & $\begin{array}{l}-0.028 \\
(0.03)\end{array}$ & $\begin{array}{l}-0.002 \\
(0.03)\end{array}$ & $\begin{array}{l}0.021 \\
(0.02)\end{array}$ & $\begin{array}{l}0.027 \\
(0.02)\end{array}$ \\
\hline sleep & $\begin{array}{l}0.341^{* *} \\
(0.11)\end{array}$ & & $\begin{array}{l}0.068 \\
(0.05)\end{array}$ & \\
\hline salary & $\begin{array}{l}-0.316^{* *} \\
(0.12)\end{array}$ & $\begin{array}{l}-0.301 * * \\
(0.12)\end{array}$ & $\begin{array}{l}-0.027 \\
(0.02)\end{array}$ & $\begin{array}{l}-0.026 \\
(0.02)\end{array}$ \\
\hline constant & $\begin{array}{l}-2.274 * * \\
(0.96)\end{array}$ & $\begin{array}{l}-2.102 * \\
(1.10)\end{array}$ & $\begin{array}{l}-0.517 \\
(0.35)\end{array}$ & $\begin{array}{l}-0.481 \\
(0.34)\end{array}$ \\
\hline$\overline{\mathrm{R}^{2}}$ & 0.231 & 0.183 & 0.365 & 0.357 \\
\hline F-test & $* * *$ & $*$ & $* *$ & $* * *$ \\
\hline $\mathrm{N}$ & 90 & 90 & 65 & 65 \\
\hline
\end{tabular}

The findings from Models 1 and 2 indicate that the more educated the employee is, the smaller is the gap between the durations of the contractual and actual working days (see Figure 2 ), and the less overtime work the employee does, although the variance is quite small. This may be because the more educated employees are better placed in the labour market and thus have better bargaining power and higher job security, in line with Otterbach (2010), who finds that concerns about losing a job explain the mismatches between actual and desired work hours. Furthermore, when employees are judged and rewarded by the satisfactory completion of tasks and projects, as outlined by Van Echtelt et al. (2006), the more educated employees may be more efficient at performing their tasks and therefore have less need to work overtime. The positive relationship between education and work outcome in the same sample of Estonian creative R\&D employees is demonstrated by Hazak, Männasoo, and Virkebau (2017).

The regression estimates from Models 1 and 2 show that the higher the salary level is, the more overtime work the employee does, although the variance is not large as shown in Figure 2. This indicates that a higher salary may increase job commitment, at least in terms of time, and 
may motivate the employees to sacrifice their leisure time for the benefit of their employer (see van Emmerik and Sanders 2005).
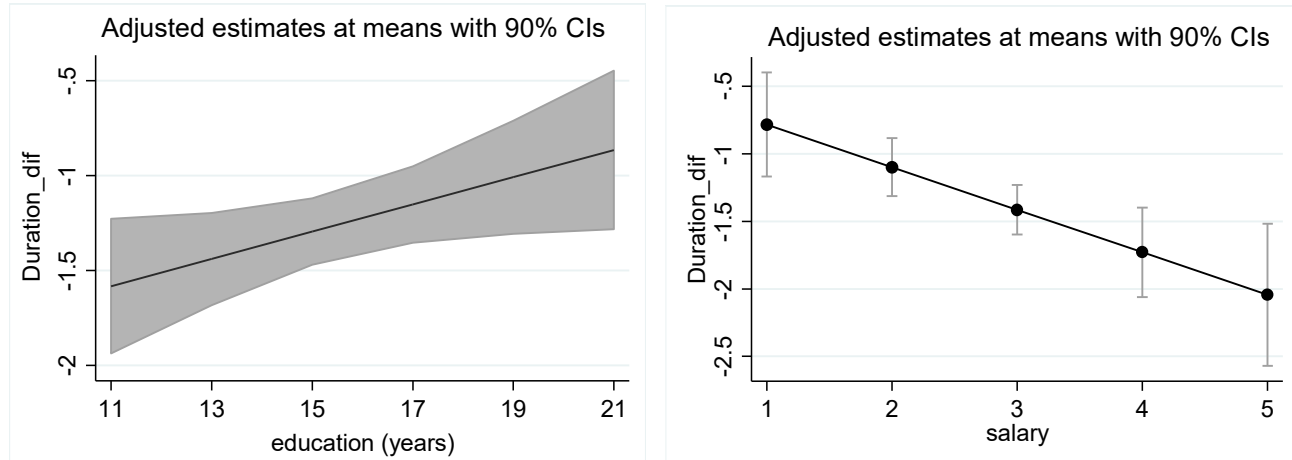

Figure 2: Difference in hours between the actual and contractual durations of the working day at different education and salary levels (with $90 \%$ confidence intervals, other variables at means)

Source: Authors 2018

We find a positive and significant relationship between sleep hours and the difference between actual and contractual working hours, meaning those who sleep less tend to do more overtime work. However there may be a reverse causality in that relationship, so the more hours the employees work, the less time they have for sleep.
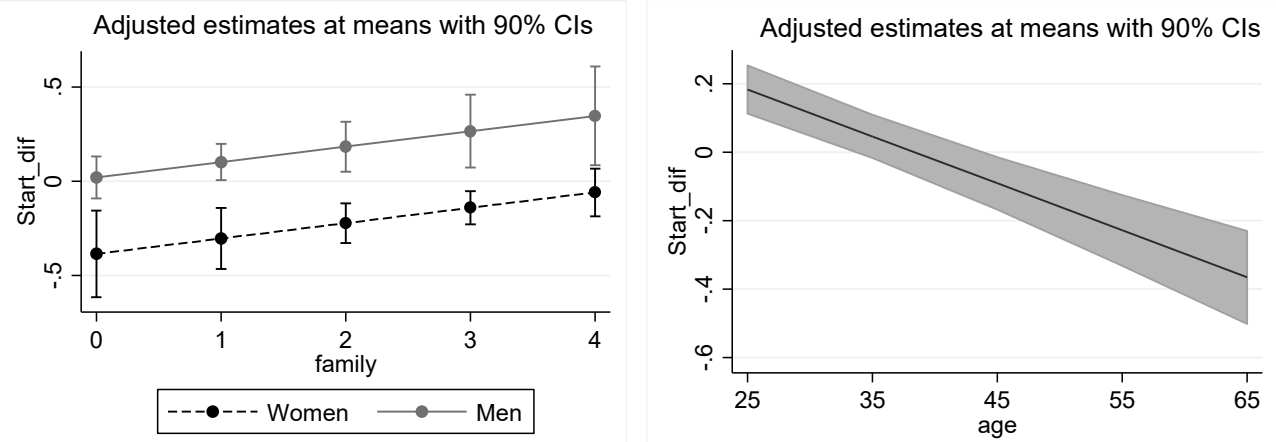

Figure 3: Difference between actual and contractual working day start times with different numbers of family members for men and women and age (with $90 \%$ confidence intervals, other variables at means) Source: Authors 2018

Figure 3 outlines the difference in hours between the actual and contractual start times of the working day with different numbers of family members for men and women, and for various ages of the employee. We find that women tend to start their working day later than contractually agreed, while men start their working day on average earlier than the contractual time. Moreover, the more family members the employee has, the more the actual start time of the working day shifts earlier from the contractual time, although the shift is quite small. It could be that family obligations drive that shift as well as gender differences. It is also worth mentioning that findings for how young children impact the use of flexitime have been mixed in the previous literature (e.g. Virkebau and Hazak 2017; Sharpe, Hermsen, and Billings 2002), which indicates that the decision to use flexitime or not may be driven by the match between work schedules and family time, with family time impacting the actual start time of the working day.

Both Model 3, where sleeping hours is included as an explanatory variable, and Model 4, where sleeping hours is excluded, reveal that the older the employee is, the later the start of their working day is from the contractually agreed start time. This may indicate that younger 
employees abide by official work schedules more strictly because they have been in the labour market for fewer years and could therefore have less negotiating power and be more diligent. As older employees have previously been found to prefer to have fewer working hours (e.g. van Wanrooy 2013; Sousa-Poza and Henneberger 2000), starting the working day later than contractually agreed may be a way for them to reduce the actual duration of the working day a little. However, when interpreting the results, the small sample size of our study should be noted.

The results of this exploratory pilot study may be useful for employers of creative knowledge employees in designing not only contractual work arrangements but also in reconsidering various norms and behaviours in their organisations that could help to address the discrepancies between the desired, actual and contractually required working hours. The significant differences identified in this study between the actual and desired working schedules reveal labour market inefficiencies that may pose constraints on employment options for employees with different working time preferences. Another potential result is that wages may be suboptimal, meaning that employees may desire extra compensation for their working hours not being aligned with their preferences, while their work contribution may be no higher than if they could work at the desired time and could be even lower. Suboptimal wages would in turn have clearly negative implications for financial results and for competitiveness.

The large mismatch between the actual and contractually agreed durations of the working day and in its start time may result in legal risks for the employees as well as for the employers. Moreover, the large amount of overtime work may lead to health risks for knowledge employees. Rethinking the contractual arrangements of knowledge work would be necessary to ensure that creative employees, the nature of their work permitting, could work at their preferred times, which may help their employers to improve their operational and financial performance.

\section{Conclusion}

Our study on a sample of Estonian creative research and development employees indicated considerable disparities between their actual, contractual, and desired working schedules. A majority of the employees in the sample work more than contractually agreed, and it appears from the regression models presented in the article that education and salary levels help to explain which types of employee tend to be more exposed to these disparities. Although it remains outside the scope of our study, past research suggests that working a significant amount of overtime may result in health risks for creative knowledge employees, which may lead to adverse operational and financial consequences for their employers in the longer term. In line with the previous literature, we find that for a large part of the employees studied there was a difference between the actual start and end times of the working day and the desired times. Nearly two thirds of the employees studied have a mismatch between their contractually agreed start and end times and their desired times, indicating that the contractual arrangement of working hours may severely constrain the use of desired work schedules. Interestingly, a majority of the knowledge employees in our sample who have flexible working schedules still follow working schedules that are quite similar to the standard nine-to-five, although the timing they desire for their work may be different. Various social norms and family commitments may explain these discrepancies.

Regression estimates for the difference between the actual and contractual start times of the working day show women tend to start their working day later after the contractual start time than men do. The more family members the employee has, the more the actual start time of the working day shifted earlier than the contractual time, while the opposite relationship was found for age. However, when interpreting the results, it should be noted that the sample for our study is small and there may be some sample selection biases.

Rethinking contractual arrangements for knowledge work would be necessary to make sure that creative employees could work at the times they prefer if the nature of their work permits. 
That may help not only to achieve improvements in the wellbeing of the employees, but also to enhance the operational and financial performance of their employers.

\section{Acknowledgement}

This project has received funding from the European Union's Horizon 2020 research and innovation programme under the Marie Skłodowska-Curie grant agreement No. 734712. The authors gratefully acknowledge support from grant PUT315 provided by the Estonian Research Council and support from the Doctoral School in Economics and Innovation, supported by the European Union, European Regional Development Fund (Tallinn University of Technology ASTRA project "TTÜ Development Program 2016-2022," project code: 2014-2020.4.01.160032). This research project was approved by the Tallinn Medical Research Ethics Committee on February 9, 2015, by decision No. 894. 


\section{REFERENCES}

Adan, Ana, and Helena Almirall. 1991. "Horne \& Östberg Morningness-Eveningness Questionnaire: A Reduced Scale." Personality and Individual Differences 12 (3): 24153.

Avarmaa, Mari, Aaro Hazak, and Kadri Männasoo. 2013. "Does Leverage Affect Labour Productivity? A Comparative Study of Local and Multinational Companies of the Baltic Countries." Journal of Business Economics and Management 14 (2): 252-75.

Barnay, Thomas. 2016. "Health, Work and Working Conditions: A Review of the European Economic Literature." The European Journal of Health Economics 17 (6): 693-709.

Bell, David, Steffen Otterbach, and Alfonso Sousa-Poza. 2012. "Work Hours Constraints and Health." Annals of Economics and Statistics: 35-54.

Bryan, Mark L. 2007. "Workers, Workplaces and Working Hours.” British Journal of Industrial Relations 45 (4): 735-59.

Böheim, René, and Taylor, Mark P. 2004. "Actual and Preferred Working Hours." British Journal of Industrial Relations 42 (1): 149-66.

Coenen, Marja, and Robert AW Kok. 2014. "Workplace Flexibility and New Product Development Performance: The Role of Telework and Flexible Work Schedules." European Management Journal 32(4): 564-76.

Green, Francis, and Nicholas Tsitsianis. 2005. "An Investigation of National Trends in Job Satisfaction in Britain And Germany." British Journal of Industrial Relations 43 (3): 401-29.

Hazak, Aaro. 2008. "Profit vs. Distributed Profit Based Taxation and Companies' Capital Structure." International Journal of Entrepreneurship and Innovation Management 8 (5): 524-41.

Hazak, Aaro, Erve Sõõru, Heili Hein, and Kadri Männasoo. Forthcoming. "Effects of Work Arrangements on the Sleep Regimen of Creative R\&D Employees." International Journal of Occupational Safety and Ergonomics.

Hazak, Aaro, Kadri Männasoo, and Marko Virkebau. 2017. "Effects of Work Arrangements on Creative R\&D Work Outcomes." Eastern European Economics 55 (6): 500-21.

Hazak, Aaro, Piia Tint, Marko Virkebau, Viive Pille, Viiu Tuulik, and Erve Sõõru. 2016. "Social Innovation Potential in Working Arrangements of R\&D Employees: Repeated Employee Survey from Estonia." 2016 IEEE International Conference on Emerging Technologies and Innovative Business Practices for the Transformation of Societies (EmergiTech), 210-13.

Hazak, Aaro, Raul Ruubel, and Marko Virkebau. Forthcoming. "When Would Creative R\&D Employees Like to Work?" International Journal of Organizational Analysis.

Kelliher, Clare, and Deirdre Anderson. 2008. "For Better or for Worse? An Analysis of How Flexible Working Practices Influence Employees' Perceptions of Job Quality." The International Journal of Human Resource Management 19 (3): 419-31.

Kossek, Ellen Ernst, Alison E. Barber, and Deborah Winters. 1999. "Using Flexible Schedules in the Managerial World: The Power of Peers." Human Resource Management 38 (1): 33 46.

Kotšina, Svetlana, and Aaro Hazak. 2012. "Does Investment Intensity Impact Company Profitability? A Cross-Country Empirical Study." 2012 2nd International Conference on Economics, Trade and Development, IPEDR 36: 157-61.

Moen, Phyllis, Erin L. Kelly, Eric Tranby, and Qinlei Huang. 2011. "Changing Work, Changing Health: Can Real Work-Time Flexibility Promote Health Behaviors and Well-Being?" Journal of Health and Social Behavior 52 (4): 404-29. 
Männasoo, Kadri, and Jaanika Meriküll. 2014. "R\&D, Credit Constraints, and Demand Fluctuations: Comparative Micro Evidence from Ten New EU Members." Eastern European Economics 52 (2): 49-64.

Männasoo, Kadri, Peeter Maripuu, and Aaro Hazak. 2018. "Investments, Credit, and Corporate Financial Distress: Evidence from Central and Eastern Europe." Emerging Markets Finance and Trade 54 (3): 677-89.

Nätti, Joukko, Timo Anttila, and Mia Tammelin. 2012. "Knowledge Work, Working Time, and Use of Time Among Finnish Dual-Earner Families: Does Knowledge Work Require The Marginalization of Private Life?" Journal of Family Issues 33 (3): 295-315.

Otterbach, Steffen. 2010. "Mismatches between Actual and Preferred Work Time: Empirical Evidence of Hours Constraints in 21 Countries." Journal of Consumer Policy 33 (2): 143-61.

Sharpe, Deanna L., Joan M. Hermsen, and Jodi Billings. 2002. "Factors Associated with Having Flextime: A Focus on Married Workers." Journal of Family and Economic Issues 23 (1): $51-72$.

Sousa-Poza, Alfonso, and Fred Henneberger. 2000. "Work Attitudes, Work Conditions and Hours Constraints: An Explorative, Cross-national Analysis." Labour 14 (3): 351-72.

Tan, Teck Yong. 2018. "Contracting with Strategic Ignorance and the Ratchet Effect of Innovation" Working Paper. http://www.teckyongtan.site/.

Van Echtelt, Patricia E., Arie C. Glebbeek, and Siegwart M. Lindenberg. 2006. "The New Lumpiness of Work: Explaining the Mismatch between Actual and Preferred Working Hours." Work, Employment and Society 20 (3): 493-512.

Van Emmerik, I. J., and Karin Sanders. 2005 "Mismatch in Working Hours and Affective Commitment: Differential Relationships for Distinct Employees Groups." Journal of Managerial Psychology 20 (8): 712-26.

van Wanrooy, Brigid. 2007. "A Desire for 9 to 5: Australians' Preference for a Standard Working Week." Labour \& Industry: A Journal of the Social and Economic Relations of Work 17 (3): 71-95.

Virkebau, Marko, and Aaro Hazak. 2017. "What Type of Research and Development Employees Use Flextime?.” The International Journal of Organizational Diversity 17 (2): 1-9.

Väisänen, Mia, and Jouko Nätti. 2002. "Working Time Preferences in Dual-Earning Households." European Societies 4 (3): 307-29.

\section{ABOUT THE AUTHORS}

Raul Ruubel: PhD Student, Department of Economics and Finance, Tallinn University of Technology, Tallinn, Estonia

Aaro Hazak: Professor, Department of Economics and Finance, Tallinn University of Technology, Tallinn, Estonia 
Knowledge Management: An International Journal is one of three thematically focused journals that support The Organization Studies Research Network-its journals, book series, conference, and online community. The journal investigates the dynamics of the contemporary "knowledge economy" and the ways in which knowledge has become a key factor of production.

As well as papers of a traditional scholarly type, this journal invites case studies that take the form of presentations of management practice-including documentation of organizational practices and exegeses analyzing the effects

Knowledge Management: An International Journal is a peer-reviewed, scholarly journal. 